\title{
RESEARCH
}

\section{Elevated serum neuregulin 4 levels in patients with hyperthyroidism}

\author{
Min Li ${ }^{1} *$, Ying Chen ${ }^{1, *}$, Jingjing Jiang ${ }^{1}$, Yan Lu ${ }^{1}$, Zhiyi Song ${ }^{2}$, Shengjie Zhang ${ }^{3}$, Chao Sun ${ }^{3}$, Hao Ying ${ }^{3}$, Xiaofang Fan ${ }^{4}$, \\ Yuping Song ${ }^{4}$, Jialin Yang ${ }^{4}$ and Lin Zhao ${ }^{1}$ \\ 1'Department of Endocrinology and Metabolism, Fudan Institute of Metabolic Diseases, Zhongshan Hospital, Fudan University, Shanghai, China \\ 2Department of Endocrinology and Metabolism, Shanghai General Hospital, Shanghai Jiao Tong University School of Medicine, Shanghai, China \\ ${ }^{3}$ CAS Key Laboratory of Nutrition, Metabolism and Food Safety, Shanghai Institutes for Biological Sciences, University of Chinese Academy of Sciences, \\ Shanghai, China \\ ${ }^{4}$ Department of Endocrinology and Metabolism, Minhang Branch, Zhongshan Hospital, Central Hospital of Minhang District, Shanghai Minhang Hospital, \\ Fudan University, Shanghai, China
}

Correspondence should be addressed to Y Song or J Yang or L Zhao: yupingsong@hotmail.com or jialinyang2002@163.com or zhao_lin2005@hotmail.com

*(M Li and Y Chen contributed equally to this work)

\begin{abstract}
Objective: Recent studies have shown that neuregulin 4 (Nrg4), a member of the epidermal growth factor (EGF) family of extracellular ligands, plays an important role in the prevention of obesity, insulin resistance and nonalcoholic fatty liver disease (NAFLD). Considering that thyroid hormone $(\mathrm{TH})$ has profound effects on whole-body energy metabolism, we speculate that circulating Nrg4 levels might be altered in patients with hyperthyroidism.

Design and methods: A total of 129 hyperthyroid patients and 100 healthy subjects were recruited. Of them, 39 hyperthyroid patients received thionamide treatment for 3 months until euthyroidism. Serum Nrg4 levels were determined using the ELISA method. To further confirm the relationship between TH and Nrg4, C57BL/6 mice were treated with $\mathrm{T}_{3}$ and quantitative real-time PCR was performed to detect Nrg4 gene expression.

Results: Serum Nrg4 levels were significantly elevated in hyperthyroid patients as compared with normal controls (3.84 \pm 1.63 vs $2.21 \pm 1.04 \mathrm{ng} / \mathrm{mL}, P<0.001)$. After achieving euthyroidism by thionamide treatment, serum Nrg4 levels dropped markedly from $3.57 \pm 1.26$ to $1.94 \pm 0.72 \mathrm{ng} / \mathrm{ml}(P<0.001)$. After adjustment for potential confounders, serum Nrg4 levels were independently associated with hyperthyroidism. The upregulation of Nrg4 expression in the livers and white adipose tissues by $\mathrm{T}_{3}$ was further confirmed by animal and cell culture experiments.

Conclusions: Serum Nrg4 levels were increased in patients with hyperthyroidism. The liver and white adipose tissue might be primary sources contributing to elevated serum Nrg4 concentrations.
\end{abstract}

\section{Key Words \\ - thyroid \\ - metabolism}

Endocrine Connections (2019) 8, 728-735

\section{Introduction}

Thyroid hormone (TH) is required for both normal development and metabolism $(1,2)$, acting through its two receptor isoforms, $\alpha$ and $\beta$. TR $\alpha$ is mainly expressed in the skeletal muscle, adipose tissue and heart, whereas TR $\beta$ is mainly expressed in the liver $(1,2)$. Hyperthyroidism, a state of excessive $\mathrm{TH}$, is characterized by increased resting https://ec.bioscientifica.com

https://doi.org/10.1530/EC-19-0175 (c) 2019 The authors Published by Bioscientifica Ltd

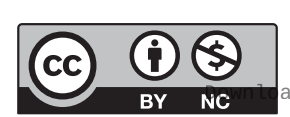

This work is licensed under a Creative Commons Attribution-NonCommercial 4.0 International License. ded from Bioscientifica.com at 04/26/2023 05:51:27AM 
energy expenditure, weight loss, reduced cholesterol levels, enhanced lipolysis and hepatic gluconeogenesis (3). Besides, recent studies have shown that altered thyroid status can affect circulating levels of several cytokines, including fibroblast growth factor 21 (FGF21), Fetuin A and Irisin $(4,5,6,7,8)$, suggesting that these cytokines may be involved in the TH signaling network to modulate whole-body glucose and lipid homeostasis.

Neuregulin 4 (Nrg4), the fourth member of the neuregulin family, was originally identified in 1999 in adult pancreas (9). Nrg4 shares a common structure of epidermal growth factor (EGF)-like domains with other family members and activates type- 1 growth factor receptors (ErbB3 and ErbB4 receptor) through tyrosine phosphorylation $(9,10)$. Subsequent studies showed that $\mathrm{Nrg} 4$ was expressed in some types of human malignancy and associated with high-grade tumors, suggesting its potential roles in cancer initiation and progression (11, 12 , 13). Interestingly, recent studies demonstrated that $\mathrm{Nrg} 4$ is also highly expressed in metabolic organs or tissues, especially enriched in brown adipose tissues (BATs) and can be secreted as an adipokine $(14,15,16)$. The BAT-derived Nrg4 activates ErbB3 and ErbB4 signaling in hepatocytes to inhibit hepatic lipogenesis and antagonize obesity-associated liver steatosis and insulin resistance $(14,15)$. Further studies showed that overexpression of $\mathrm{Nrg} 4$ reduces fat mass, increases energy expenditure and protects mice from high-fat-diet-induced obesity in part through activation of fatty acid oxidation and eliciting a healthy adipokine profile $(17,18)$. In contrast, mice depleted of Nrg4 or ErbB4 developed metabolic disorders as shown by development of obesity, dyslipidemia, hepatic steatosis, hyperglycemia, hyperinsulinemia and insulin resistance $(14,19)$.

Considering that both $\mathrm{TH}$ and $\mathrm{Nrg} 4$ have some overlap in metabolic effects, including the prevention of obesity and enhancing energy expenditure, we therefore tested the hypothesis that $\mathrm{TH}$ may increase circulating Nrg4 levels in humans and further characterize the source of Nrg4 in mice.

\section{Subjects and methods}

\section{Human subjects}

A total of 129 patients with hyperthyroidism were recruited from the Department of Endocrinology and Metabolism, Zhongshan Hospital (Shanghai, China) and Minhang Branch, Zhongshan Hospital (Shanghai, China).
Hyperthyroidism was diagnosed by typical clinical presentation, elevated serum $\mathrm{TH}$, reduced thyroidstimulating hormone (TSH) and elevated serum TSH receptor antibody (TRAb) levels. One hundred healthy controls were recruited from Department of Physical Examination Center, Zhongshan Hospital. Subjects with the following conditions were excluded: type 2 diabetes, cancer, pregnancy, lactation, subacute thyroiditis, abnormal liver function, abnormal renal function and infectious diseases. Thirty-nine hyperthyroid patients received thionamide treatment for 3 months and their TH levels reached the normal range. The study protocol was approved by the Human Research Ethical Committee of Zhongshan Hospital. All subjects provided written informed consents.

\section{Anthropometric and biochemical measurements}

Body weight and height were obtained in light clothes and bare feet to the nearest $0.1 \mathrm{~kg}$ and $0.1 \mathrm{~cm}$, respectively. Body mass index (BMI) was derived from weight in kilograms divided by square of height in meters. Fasting venous blood samples were collected from 08:00 to 09:00 h after a 12-h overnight fast. Serum triglyceride (TG), total cholesterol (TC), high-density lipoprotein cholesterol (HDL-C), alanine transaminase (ALT), aspartate aminotransferase (AST), total bilirubin (TBIL) and direct bilirubin (DBIL) levels were measured with an autoanalyzer (Modular E170, Roche). Fasting blood glucose (FBG) was measured by glucose oxidase method on an auto-analyzer (Modular P800, Roche). Fasting insulin, free $\mathrm{T}_{3}$, free $\mathrm{T}_{4}$ and TSH concentrations were measured by using electrochemiluminescence assays (Modular E170, Roche). The homeostasis model assessment of insulin resistance index (HOMA_IR) was calculated as fasting insulin $(\mu \mathrm{IU} / \mathrm{ml}) \times$ fasting glucose $(\mathrm{mmol} / \mathrm{L}) / 22.5$. Serum $\mathrm{Nrg} 4$ concentrations were measured using ELISA kits from Phoenix Pharmaceuticals Inc. (EK-056-24).

\section{Animal experiments}

Male C57BL/6 mice aged 8-10 weeks were housed at $22 \pm 1{ }^{\circ} \mathrm{C}$ with a humidity of $35 \pm 5 \%$ under a 12 -h darkness/light cycle in a specific pathogen-free animal facility. Fifteen mice were divided into three groups and were injected intraperitoneally with either vehicle control (saline) or 3,3',5-triiodo-L-thyronine $\left(\mathrm{T}_{3}, 0.5 \mathrm{mg} / \mathrm{kg}\right.$, \#fT2877, Sigma-Aldrich) for $4 \mathrm{~h}$ (single injection) or 5 days (once daily). The primary hepatocytes were isolated as described previously (20) and maintained 
in DMEM medium containing 10\% fetal bovine serum. The fetal bovine serum was stripped with $10 \%$ resin to remove TH before use. Then cells were treated with either vehicle or $100 \mathrm{nM} \mathrm{T}_{3}$ for $6 \mathrm{~h}$. All protocols were approved by the Institutional Animal Care and Use Committee of Zhongshan Hospital, Fudan University (Shanghai, China).

\section{RNA extraction and quantitative real-time PCR}

Total RNA was isolated from tissues or primary hepatocytes using TRIzol (Invitrogen) following the manufacturer's instructions. Quantitative real-time PCR was performed using a SYBR Green Premix Ex Taq (Takara) on Light Cycler480 (Roche). The primers were selected from PrimerBank (https://pga.mgh.harvard.edu/primerbank/): Nrg4 (Forward: 5'-ATGCCAACAGATC ACGAAGAG-3'; Reverse: 5'-AATGGGCTGGGAATAGTAGGT-3'); 36B4 (Forward: 5'-AGCCCAGAACACTGGTCTC-3'; Reverse: 5'-ACTCAGGATTTCAA TGGTGCC-3'). The quantitative analysis of gene expression data was conducted using the $2^{-\Delta \Delta \mathrm{Ct}}$ method.

\section{Statistical analysis}

All statistical analyses were performed using SAS 9.3 (SAS Institute). Normally distributed continuous variables were presented as means with standard deviations (s.D.), whereas skewed distributed continuous variables were presented as geometrical median and interquartile range. $\chi^{2}$ and one-way ANOVA tests were used for comparison of categorical and continuous variables, respectively. The Student's paired $t$ test was used for comparison of the data before and after anti-thyroid treatment. Skewed variables such as TSH and TPOAb were log-transformed before the analysis. Multivariate linear regression models were used to investigate the association of the following variables with Nrg4: BMI, free T3, free T4, TC, TG, HDL-C, ALT, AST, TBIL, DBIL, FBG, FINS. Multivariable logistic regression was performed to calculate the adjusted ORs and 95\% CIs. A two-sided $P<0.05$ was considered statistically significant.

\section{Results}

\section{Elevated serum Nrg4 levels in hyperthyroid subjects}

The clinical characteristics of subjects in this study has been displayed in Table 1 . The age and gender were comparable between hyperthyroid patients and normal subjects.
Table 1 Clinical and biochemical features of hyperthyroid patients and control subjects.

\begin{tabular}{|c|c|c|c|}
\hline Variables & Control & Hyperthyroid patients & $P$ value \\
\hline $\mathrm{N}$ & 100 & 129 & \\
\hline Nrg4 (ng/ml) & $2.21 \pm 1.04$ & $3.84 \pm 1.63$ & $<0.001$ \\
\hline Free $T_{3}, \mathrm{pmol} / \mathrm{L}$ & $5.4 \pm 0.4$ & $31.5 \pm 12.1$ & $<0.001$ \\
\hline Free $\mathrm{T}_{4}, \mathrm{pmol} / \mathrm{L}$ & $16.4 \pm 2.9$ & $82.1 \pm 36.4$ & $<0.001$ \\
\hline $\mathrm{TSH}, \mathrm{mIU} / \mathrm{L}$ & $1.66(0.98,2.32)$ & $0.01(0.01,0.01)$ & $<0.001$ \\
\hline TGAb, IU/mL & $10.2 \pm 3.1$ & $34.2 \pm 10.6$ & $<0.001$ \\
\hline TPOAb, IU/mL & $4.20(3.52,4.66)$ & $198.19(116.51,265.46)$ & $<0.001$ \\
\hline Age, years & $33 \pm 5$ & $34 \pm 5$ & 0.166 \\
\hline $\begin{array}{l}\text { Gender, } \\
\text { male/female }\end{array}$ & $65 / 35$ & $85 / 44$ & 0.890 \\
\hline $\mathrm{BMI}, \mathrm{kg} / \mathrm{m}^{2}$ & $22.7 \pm 1.5$ & $21.0 \pm 2.1$ & $<0.001$ \\
\hline $\mathrm{TC}, \mathrm{mmol} / \mathrm{L}$ & $4.61 \pm 0.53$ & $3.46 \pm 0.77$ & $<0.001$ \\
\hline $\mathrm{TG}, \mathrm{mmol} / \mathrm{L}$ & $1.13 \pm 0.31$ & $1.17 \pm 0.34$ & 0.363 \\
\hline $\mathrm{HDL}-\mathrm{C}, \mathrm{mmol} / \mathrm{L}$ & $1.24 \pm 0.34$ & $1.18 \pm 0.45$ & 0.209 \\
\hline $\mathrm{ALT}, \mathrm{U} / \mathrm{L}$ & $23.6 \pm 5.3$ & $35.0 \pm 9.8$ & $<0.001$ \\
\hline AST, U/L & $26.7 \pm 10.0$ & $41.5 \pm 11.5$ & $<0.001$ \\
\hline $\mathrm{TBIL}, \mu \mathrm{mol} / \mathrm{L}$ & $13.2 \pm 5.9$ & $13.9 \pm 5.1$ & 0.325 \\
\hline $\mathrm{DBIL}, \mu \mathrm{mol} / \mathrm{L}$ & $2.90 \pm 1.05$ & $2.65 \pm 1.29$ & 0.117 \\
\hline $\mathrm{FBG}, \mathrm{mmol} / \mathrm{L}$ & $5.18 \pm 0.49$ & $5.30 \pm 0.59$ & 0.116 \\
\hline FINS, mU/L & $10.7 \pm 4.1$ & $12.4 \pm 4.6$ & 0.003 \\
\hline HOMA_IR & $2.44 \pm 0.94$ & $2.93 \pm 1.08$ & 0.001 \\
\hline Heart rate, bpm & $77 \pm 11$ & $109 \pm 13$ & $<0.001$ \\
\hline
\end{tabular}

Data are expressed as mean \pm S.D.

ALT, alanine transaminase; AST, aspartate aminotransferase; BMI, body mass index; DBIL, direct bilirubin; FBG, fasting blood glucose; FINS, fasting insulin; HDL-C, high-density lipoprotein cholesterol; HOMA_IR, the homeostasis model assessment of insulin resistance index; Nrg4, neuregulin 4; TBIL, total bilirubin; TC, total cholesterol; TG, triglyceride; TGAb, thyroglobulin antibody; TPOAb, anti-thyroid peroxidase antibody; $\mathrm{TSH}$, thyroid-stimulating hormone.

Patients with hyperthyroidism exhibited increased levels of free $\mathrm{T}_{3}$, free $\mathrm{T}_{4}$, ALT, AST, FINS, HOMA_IR and heart rate, decreased levels of BMI, TC and TSH. Besides, serum TG, HDL-C, TBIL, DBIL and FBG levels were generally the same between the case-control groups. As shown in Table 1, serum Nrg4 concentrations were dramatically increased in hyperthyroid patients compared with normal subjects $(3.84 \pm 1.63$ vs $2.21 \pm 1.04, P<0.001)$.

\section{Association of serum Nrg4 levels with hyperthyroidism}

In all the subjects, serum Nrg4 levels were positively correlated with free $\mathrm{T} 3$, free $\mathrm{T}_{4}$, TPOAb and TGAb levels (Fig. 1A, B, C and D, $P<0.001$ ). Moreover, serum Nrg4 levels were negatively correlated with TSH and TC levels (Fig. $1 \mathrm{E}$ and $\mathrm{F}, \mathrm{P}<0.001)$. In the multivariate linear regression model, FT3 and AST were positively associated with Nrg4 (Table 2).

Further logistic regression models were performed to explore the unadjusted and adjusted ORs with associated 95\% CI of serum Nrg4 for hyperthyroidism (Table 3).
This work is licensed under a Creative Commons Attribution-NonCommercial 4.0 International License. ded from Bioscientifica.com at 04/26/2023 05:51:27AM via free access 
A

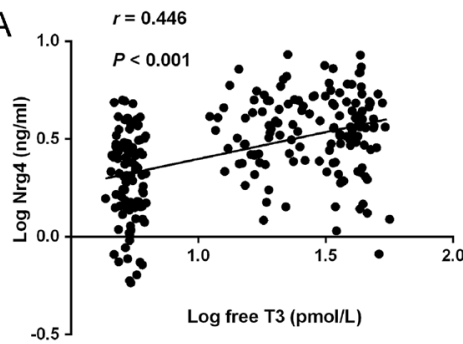

$\mathrm{D}$

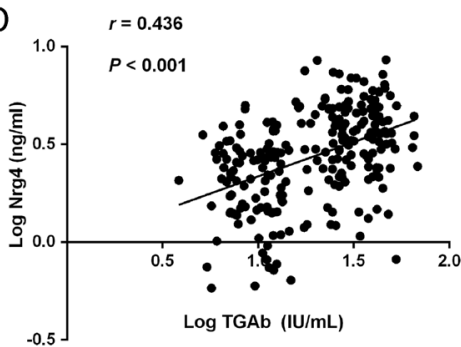

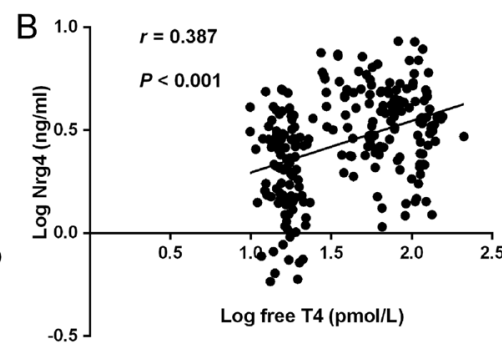

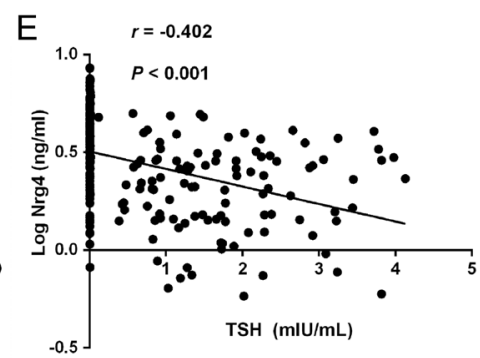

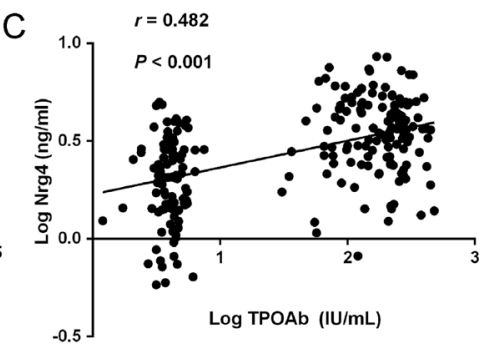

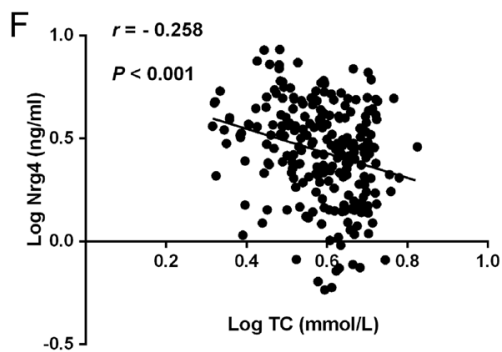

Figure 1

Correlation of Nrg4 with serum levels of free T4 (A), free T3 (B), TPOAb (C), TGAb (D), TSH (E) and total cholesterol (TC) (F).

In model 1, with no adjustment for any confounding factor, per SD increase of serum Nrg4 levels was significantly associated with hyperthyroidism (OR, 4.89; 95\% CI, 3.16-8.02; $P<0.001)$. In model 2 , after adjustment for age, gender and BMI, per SD increase of serum Nrg4 levels was also significantly associated with hyperthyroidism (OR, 5.62; 95\% CI, 3.41-10.01; $P<0.001)$. In model 3, after further adjustment for ALT, AST, FBG, FINS and TC, per SD increase of serum Nrg4 levels remained independently associated with hyperthyroidism, with the adjusted OR (95\% CI) of $5.86(2.32-18.37)(P<0.001)$.

\section{Reduced serum Nrg4 levels in patients after thionamide treatment}

Furthermore, 39 hyperthyroidism patients received thionamide treatment and euthyroid levels were achieved after 3 months. Accordingly, free $\mathrm{T}_{3}$, free $\mathrm{T}_{4}$, ALT, AST and heart rate were decreased, whereas body weight, TC and TSH were increased. In parallel, serum Nrg4 concentration were dramatically decreased in patients after thionamide treatment $(3.57 \pm 1.26$ vs $1.94 \pm 0.72, P<0.001)$ (Table 4$)$.

\section{TH treatment upregulates Nrg4 expression in mice}

To determine which organ or tissue may contribute to the elevated circulating $\mathrm{Nrg} 4$ in hyperthyroid patients, C57BL/6 mice were treated with $\mathrm{T}_{3}$ intraperitoneally for $4 \mathrm{~h}$ to evaluate the acute effect or once daily for 5 days to evaluate chronic effect, respectively. As shown in
Fig. 2A and B, mRNA levels of Nrg4 were moderately but significantly induced in the inguinal and epididymal white adipose tissues (WATs) after administration of $\mathrm{T}_{3}$. Notably, its mRNA expression was also dramatically induced in the livers of mice treated with $\mathrm{T}_{3}$ (Fig. 2C). In agreement, $\mathrm{T}_{3}$ treatment increased Nrg4 mRNA levels in mouse primary hepatocytes (Fig. 2D). In contrast, its expression in the BATs and skeletal muscles (SKMs) were not altered (Fig. 2E and F). Therefore, our results suggest that the WAT and liver appear to be the primary source for circulating $\mathrm{Nrg} 4$ levels by $\mathrm{T}_{3}$ treatment. Serum Nrg4 levels were not determined because a reliable immunoassay for mouse circulating Nrg4 was not available at present (14).

Table 2 Multiple linear regression analysis of variables associated with serum Nrg4.

\begin{tabular}{|c|c|c|}
\hline & $\beta \pm$ S.E. & $P$ value \\
\hline $\mathrm{BMI}, \mathrm{kg} / \mathrm{m}^{2}$ & $-0.02 \pm 0.05$ & 0.66 \\
\hline Free $T_{3}, \mathrm{pmol} / \mathrm{L}$ & $0.04 \pm 0.01$ & $<0.01$ \\
\hline Free $\mathrm{T}_{4}, \mathrm{pmol} / \mathrm{L}$ & $-0.002 \pm 0.003$ & 0.52 \\
\hline $\mathrm{TC}, \mathrm{mmol} / \mathrm{L}$ & $-0.07 \pm 0.13$ & 0.59 \\
\hline $\mathrm{TG}, \mathrm{mmol} / \mathrm{L}$ & $-0.30 \pm 0.30$ & 0.31 \\
\hline $\mathrm{HDL}-\mathrm{C}, \mathrm{mmol} / \mathrm{L}$ & $0.45 \pm 0.24$ & 0.06 \\
\hline $\mathrm{ALT}, \mathrm{U} / \mathrm{L}$ & $0.005 \pm 0.01$ & 0.69 \\
\hline AST, U/L & $0.03 \pm 0.01$ & 0.01 \\
\hline $\mathrm{TBIL}, \mu \mathrm{mol} / \mathrm{L}$ & $0.005 \pm 0.02$ & 0.77 \\
\hline $\mathrm{DBIL}, \mu \mathrm{mol} / \mathrm{L}$ & $-0.05 \pm 0.08$ & 0.52 \\
\hline $\mathrm{FBG}, \mathrm{mmol} / \mathrm{L}$ & $-0.20 \pm 0.18$ & 0.25 \\
\hline FINS, mU/L & $-0.02 \pm 0.02$ & 0.32 \\
\hline
\end{tabular}

$\beta$, regression coefficient. 
Table 3 ORs for association of serum Nrg4 levels with hyperthyroidism.

\begin{tabular}{|c|c|c|}
\hline Variable & OR $(95 \% \mathrm{Cl})$ & $P$ value \\
\hline \multicolumn{3}{|l|}{ Model 1} \\
\hline Nrg4 $4^{a}$ & 4.89 (3.16-8.02) & $<0.01$ \\
\hline \multicolumn{3}{|l|}{ Model 2} \\
\hline $\mathrm{Nrg}^{\mathrm{a}}$ & $5.62(3.41-10.01)$ & $<0.01$ \\
\hline Age & $1.03(0.97-1.11)$ & 0.34 \\
\hline $\begin{array}{l}\text { Gender (female vs } \\
\text { male) }\end{array}$ & $0.69(0.32-1.47)$ & 0.34 \\
\hline $\mathrm{BMI}$ & $0.56(0.46-0.70)$ & $<0.01$ \\
\hline \multicolumn{3}{|l|}{ Model 3} \\
\hline $\mathrm{Nrg}^{\mathrm{a}}$ & $5.86(2.32-18.37)$ & $<0.01$ \\
\hline Age & $1.00(0.88-1.13)$ & 0.96 \\
\hline $\begin{array}{l}\text { Gender (female vs } \\
\text { male) }\end{array}$ & $0.37(0.09-1.47)$ & 0.16 \\
\hline $\mathrm{BMI}$ & $0.52(0.35-0.78)$ & $<0.01$ \\
\hline ALT & $1.27(1.13-1.43)$ & $<0.01$ \\
\hline AST & $1.05(0.98-1.13)$ & 0.14 \\
\hline FBG & $3.22(0.72-14.34)$ & 0.13 \\
\hline FINS & $1.12(0.96-1.32)$ & 0.15 \\
\hline TC & $0.03(0.01-0.14)$ & $<0.01$ \\
\hline
\end{tabular}

${ }^{\mathrm{a}} \mathrm{OR}$ and $95 \% \mathrm{Cl}$ expressed as per s.D. increase of $\mathrm{Nrg} 4$.

\section{Discussion}

In the present study, our results suggest that $\mathrm{TH}$ has a strong impact on the circulating Nrg4 levels. First, Nrg4 levels were significantly higher in patients with hyperthyroidism compared with euthyroid controls and dramatically decreased after thionamide treatment.

Table 4 Serum NRG4 levels before and after thionamide treatment in hyperthyroid patients.

\begin{tabular}{|c|c|c|c|}
\hline & Before & After & $P$ value \\
\hline$n$ & 39 & 39 & \\
\hline Nrg4 (ng/ml) & $3.57 \pm 1.26$ & $1.94 \pm 0.72$ & $<0.001$ \\
\hline $\begin{array}{c}\text { Free } T_{3} \\
\text { pmol/L }\end{array}$ & $27.1 \pm 20.0$ & $4.6 \pm 0.8$ & $<0.001$ \\
\hline $\begin{array}{l}\text { Free } T_{4 \prime} \\
\mathrm{pmol} / \mathrm{L}\end{array}$ & $61.3 \pm 26.6$ & $13.1 \pm 2.7$ & $<0.001$ \\
\hline TSH, mIU/L & $0.01(0.01,0.01)$ & $0.45(0.01,1.16)$ & $<0.001$ \\
\hline Weight, kg & $52.0 \pm 6.2$ & $56.8 \pm 7.3$ & $<0.001$ \\
\hline $\mathrm{ALT}, \mathrm{U} / \mathrm{L}$ & $37.7 \pm 15.9$ & $20.6 \pm 9.6$ & $<0.001$ \\
\hline AST, U/L & $31.1 \pm 11.9$ & $20.6 \pm 7.1$ & $<0.001$ \\
\hline TBIL, $\mu \mathrm{mol} / \mathrm{L}$ & $14.9 \pm 7.5$ & $12.3 \pm 4.3$ & 0.056 \\
\hline DBIL, $\mu \mathrm{mol} / \mathrm{L}$ & $4.75 \pm 3.22$ & $3.71 \pm 1.56$ & 0.069 \\
\hline $\mathrm{TC}, \mathrm{mmol} / \mathrm{L}$ & $3.71 \pm 0.81$ & $5.44 \pm 0.99$ & $<0.001$ \\
\hline TG, mmol/L & $0.99 \pm 0.72$ & $1.08 \pm 0.63$ & 0.476 \\
\hline $\begin{array}{l}\text { HDL-C, } \\
\text { mmol/L }\end{array}$ & $1.40 \pm 0.39$ & $1.66 \pm 0.33$ & 0.002 \\
\hline $\mathrm{FBG}, \mathrm{mmol} / \mathrm{L}$ & $5.20 \pm 0.70$ & $5.02 \pm 0.41$ & 0.163 \\
\hline FINS, mU/L & $11.2 \pm 13.7$ & $8.9 \pm 7.1$ & 0.340 \\
\hline HOMA_IR & $2.67 \pm 3.22$ & $2.01 \pm 1.63$ & 0.244 \\
\hline $\begin{array}{l}\text { Heart rate, } \\
\text { bpm }\end{array}$ & $112 \pm 12$ & $79 \pm 7$ & $<0.001$ \\
\hline
\end{tabular}

Data are expressed as mean \pm S.D.
Second, both correlation and logistic regression analysis confirmed the association of serum Nrg4 levels with thyroid status. Third, we showed that Nrg4 expression levels were significantly upregulated in WAT and livers in mice by both acute and chronic $\mathrm{T}_{3}$ treatment. Finally, we provided ex vivo evidence showing that Nrg4 expression in primary hepatocytes were also induced by $\mathrm{T}_{3}$ treatment. Therefore, our results provide the clinical, animal and cellular results showing that $\mathrm{Nrg} 4$ was associated with hyperthyroidism.

Initial studies demonstrated that Nrg4 is expressed in the adult pancreas and is essential for delineation of the somatostatin-producing delta-cells in developing pancreatic islets (9). Nrg4 further obtained great attention since Wang et al. reported that Nrg4 is enriched in brown and WAT and preserves metabolic homeostasis through attenuation of hepatic lipogenesis (14). A subsequent study also proposed that hepatic Nrg4 signaling could be an endocrine checkpoint for steatosis-to-steatohepatitis progression by countering stress-induced liver injury, fibrosis and cell death (21). In addition, several studies in human cohorts revealed that Nrg4 levels were increased in patients with prediabetes, newly diagnosed diabetes, gestational diabetes or polycystic ovary syndrome, suggesting Nrg4 concentrations were associated with the development and progression of insulin resistance $(22,23,24,25)$. However, other findings indicate that circulating $\mathrm{Nrg} 4$ concentrations may be a protective factor in the development of metabolic syndrome. For instance, in newly diagnosed patients with type 2 diabetes, lower plasma Nrg4 levels were associated with elevated highsensitivity C-reactive protein (26). In obese adults, subjects with low levels of circulating Nrg4 had high prevalence of fasting glucose and blood pressure (27). Interestingly, our data found that circulating Nrg4 levels were negatively correlated with serum TC levels. Consistently, Jiang et al. reported that lower circulating $\mathrm{Nrg} 4$ concentrations are associated with subclinical atherosclerosis in obese adults, as shown by increased carotid intima-media thickness and atherosclerotic plaque (28). Therefore, circulating Nrg4 might play a protective role in cardiovascular diseases.

Our animal studies further indicate that the liver and WAT appeared to be major sources of Nrg4 in prolonged hyperthyroidism. Wang et al. reported that Nrg4 mRNA was enriched in adipose tissue and relatively lower in other tissues (14). However, Liu et al. reported that hepatic Nrg4 expression was significantly upregulated in the liver in response to experimental myocardial ischemia (29), suggesting that it may contribute to cardioprotection and could be considered for the development of

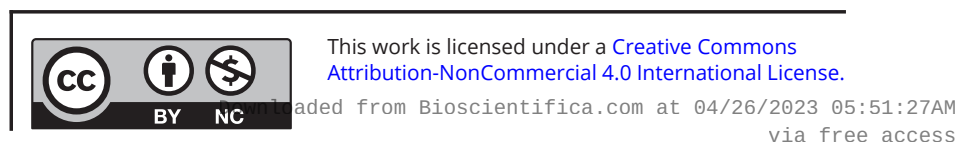


A

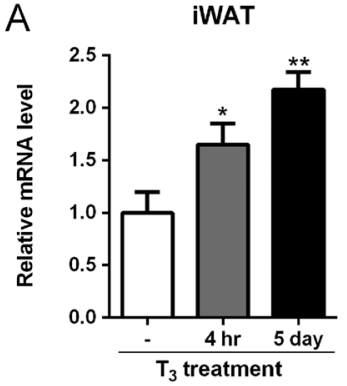

$\mathrm{D}$

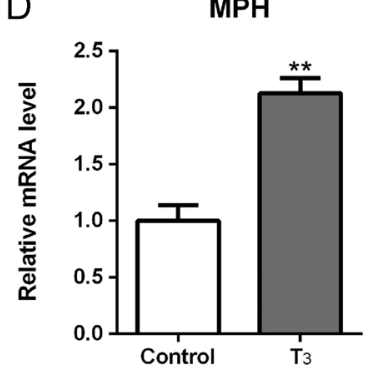

B

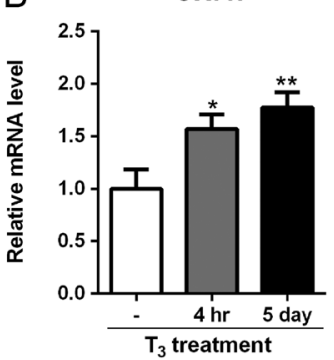

$\mathrm{E}$

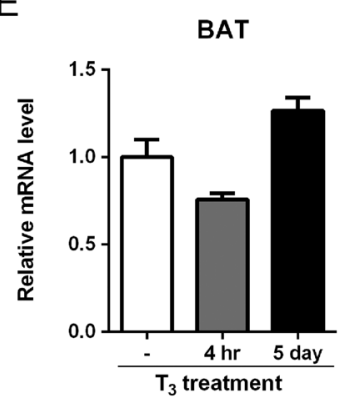

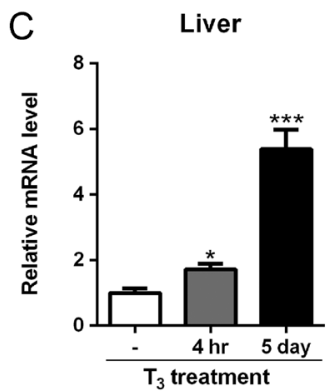

$\mathrm{F}$

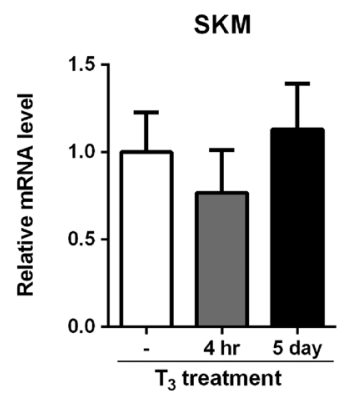

\section{Figure 2}

$\mathrm{TH}$ induces Nrg4 expression in C57BL/6 mice and primary hepatocytes. (A, B and C) Relative mRNA levels of Nrg4 in inguinal white adipose tissue (iWAT, A), epididymal white adipose tissue (eWAT, $B$ ) and liver (C) tissues of mice treated with $\mathrm{T}_{3}$ or vehicle control for $4 \mathrm{~h}$ or 5 days ( $n=5$ per group). (D) Relative mRNA levels of Nrg4 in mouse primary hepatocytes (MPH) treated with $\mathrm{T}_{3}$ for $6 \mathrm{~h}$. ( $E$ and F) Relative mRNA levels of Nrg4 in brown adipose tissue (BAT, E) and skeletal muscle (SKM, F) of mice treated with $T_{3}$ or vehicle control for $4 \mathrm{~h}$ or 5 days ( $n=5$ per group). Data are presented as means \pm standard error. ${ }^{*} P<0.05, * * P<0.01$, $\star \star \star P<0.001$. cardioprotective agents. Therefore, together with our findings, these studies indicate that the expression of $\mathrm{Nrg} 4$ in the liver might be also important under certain physiological or pathological conditions.

$\mathrm{TH}$ is required for regulating metabolism in the adult, through its two receptor isoforms, $\alpha$ and $\beta$, which are differentially expressed in tissues and have distinct functions in mediating $\mathrm{TH}$ signaling. It has been well established that $\mathrm{TH}$ status correlates with body weight and energy expenditure (30). In adipocytes, TH can directly stimulate thermogenesis in BATs and also induce WAT browning through peripheral and central mechanisms (31). In the liver, TH regulates cholesterol and bile acid homeostasis through direct actions on gene expression as well as cross-talk with other nuclear receptors (30). TH also stimulates gluconeogenesis and hepatic glucose production through the regulation of phosphoenolpyruvate carboxykinase (PEPCK) $(32,33)$. In addition, recent studies have demonstrated that impaired thyroid action is associated with nonalcoholic fatty liver disease (NAFLD), and selective TH receptor agonists have exhibited strong effects against NAFLD in preliminary clinical trials $(34,35,36)$. Taken together with the results of the current study, Nrg4 plays an important role in preserving metabolic homeostasis and have some overlap in metabolic effects with $\mathrm{TH}$, including attenuating hepatic lipogenesis (14), increasing energy expenditure $(18,37)$ and maintaining hepatic gluconeogenesis (38), it is tempting to assume that partial metabolic benefits of $\mathrm{TH}$ might be mediated by the upregulation of Nrg4 expression.
Further studies using Nrg4 knockout and transgenic mice will clarify potential metabolic mechanisms connecting Nrg4 and thyroid function/hormones.

There are several limitations of this study that we would like to point out: First, this study was crosssectional and the sample size for hypothyroid patients was relatively small. Second, the reason for the tissuespecific effects of $\mathrm{TH}$ in the regulation of $\mathrm{Nrg} 4$ expression remains explored. We analyzed the promoter (from position $-2500 \mathrm{bp}$ to transcription start site) and introns of Nrg4 gene and did not identify a classic TR response element in those regions. Therefore, whether TH activates Nrg4 mRNA transcription through a direct or indirect role needs further investigations.

In conclusion, we, for the first time to our knowledge, showed that serum Nrg4 levels are independently associated with hyperthyroidism. TH might be an important stimulus that increases endogenous Nrg4 expression.

\section{Declaration of interest}

The authors declare that there is no conflict of interest that could be perceived as prejudicing the impartiality of the research reported.

\section{Funding}

This study is supported by grants from Science and Technology Commission of Shanghai Municipality (Nos. 18dz2304400 and 15411970700), Natural Science Foundation of China (Nos. 81471016 and 81500603) and the Pujiang Talent Program from Science and Technology Commission of Shanghai Municipality.
This work is licensed under a Creative Commons Attribution-NonCommercial 4.0 International License. ded from Bioscientifica.com at $04 / 26 / 2023$ 05:51:27AM
via free access 


\section{Author contribution statement}

$Y S$, J $Y$ and $L Z$ conceived the project. M L, J J, Y L, S Z, C S and H Y performed the animal and cellular experiments. $Y C, Z S$ and $X F$ took statistical analysis. $M L, Y C, J J, Y L$ and $L Z$ drafted the manuscript. All authors reviewed the manuscript.

\section{References}

1 Yehuda-Shnaidman E, Kalderon B \& Bar-Tana J. Thyroid hormone, thyromimetics, and metabolic efficiency. Endocrine Reviews 201435 35-58. (https://doi.org/10.1210/er.2013-1006)

2 Bassett JH \& Williams GR. Role of thyroid hormones in skeletal development and bone maintenance. Endocrine Reviews 201637 135-187. (https://doi.org/10.1210/er.2015-1106)

3 Taylor PN, Albrecht D, Scholz A, Gutierrez-Buey G, Lazarus JH, Dayan CM \& Okosieme OE. Global epidemiology of hyperthyroidism and hypothyroidism. Nature Reviews: Endocrinology 201814 301-316. (https://doi.org/10.1038/nrendo.2018.18)

4 Adams AC, Astapova I, Fisher FM, Badman MK, Kurgansky KE, Flier JS, Hollenberg AN \& Maratos-Flier E. Thyroid hormone regulates hepatic expression of fibroblast growth factor 21 in a PPARalphadependent manner. Journal of Biological Chemistry 2010285 14078-14082. (https://doi.org/10.1074/jbc.C110.107375)

5 Xiao F, Lin M, Huang P, Zeng J, Zeng X, Zhang H, Li X, Yang S, $\mathrm{Li} Z$ \& Li X. Elevated serum fibroblast growth factor 21 levels in patients with hyperthyroidism. Journal of Clinical Endocrinology and Metabolism 2015100 3800-3805. (https://doi.org/10.1210/jc.20151797)

6 Bakiner O, Bozkirli E, Ertugrul D, Sezgin N \& Ertorer E. Plasma fetuin-A levels are reduced in patients with hypothyroidism. European Journal of Endocrinology 2014170 411-418. (https://doi. org/10.1530/EJE-13-0831)

7 Lin KH, Lee HY, Shih CH, Yen CC, Chen SL, Yang RC \& Wang CS. Plasma protein regulation by thyroid hormone. Journal of Endocrinology 2003179 367-377. (https://doi.org/10.1677/ joe.0.1790367)

8 Ruchala M, Zybek A \& Szczepanek-Parulska E. Serum irisin levels and thyroid function - newly discovered association. Peptides 201460 51-55. (https://doi.org/10.1016/j.peptides.2014.07.021)

9 Harari D, Tzahar E, Romano J, Shelly M, Pierce JH, Andrews GC \& Yarden Y. Neuregulin-4: a novel growth factor that acts through the ErbB-4 receptor tyrosine kinase. Oncogene 199918 2681-2689. (https://doi.org/10.1038/sj.onc.1202631)

10 Falls DL. Neuregulins: functions, forms, and signaling strategies. Experimental Cell Research 2003284 14-30. (https://doi.org/10.1016/ S0014-4827(02)00102-7)

11 Dunn M, Sinha P, Campbell R, Blackburn E, Levinson N, Rampaul R, Bates T, Humphreys S \& Gullick WJ. Co-expression of neuregulins 1, 2, 3 and 4 in human breast cancer. Journal of Pathology 2004203 672-680. (https://doi.org/10.1002/path.1561)

12 Marshall C, Blackburn E, Clark M, Humphreys S \& Gullick WJ. Neuregulins 1-4 are expressed in the cytoplasm or nuclei of ductal carcinoma (in situ) of the human breast. Breast Cancer Research and Treatment 200696 163-168. (https://doi.org/10.1007/s10549-0059073-z)

13 Hayes NV, Blackburn E, Smart LV, Boyle MM, Russell GA, Frost TM, Morgan BJ, Baines AJ \& Gullick WJ. Identification and characterization of novel spliced variants of neuregulin 4 in prostate cancer. Clinical Cancer Research 200713 3147-3155. (https://doi. org/10.1158/1078-0432.CCR-06-2237)

14 Wang GX, Zhao XY, Meng ZX, Kern M, Dietrich A, Chen Z, Cozacov Z, Zhou D, Okunade AL, Su X, et al. The brown fatenriched secreted factor Nrg4 preserves metabolic homeostasis through attenuation of hepatic lipogenesis. Nature Medicine 201420 1436-1443. (https://doi.org/10.1038/nm.3713)

15 Pfeifer A. NRG4: an endocrine link between brown adipose tissue and liver. Cell Metabolism 201521 13-14. (https://doi.org/10.1016/j. cmet.2014.12.008)

16 Christian M. Transcriptional fingerprinting of 'browning' white fat identifies NRG4 as a novel adipokine. Adipocyte 20154 50-54. (https://doi.org/10.4161/adip.29853)

17 Ma Y, Gao M \& Liu D. Preventing high fat diet-induced obesity and improving insulin sensitivity through neuregulin 4 gene transfer. Scientific Reports 20166 26242. (https://doi.org/10.1038/srep26242)

18 Chen Z, Wang GX, Ma SL, Jung DY, Ha H, Altamimi T, Zhao XY, Guo L, Zhang P, Hu CR, et al. Nrg4 promotes fuel oxidation and a healthy adipokine profile to ameliorate diet-induced metabolic disorders. Molecular Metabolism 20176 863-872. (https://doi. org/10.1016/j.molmet.2017.03.016)

19 Zeng F, Wang Y, Kloepfer LA, Wang S \& Harris RC. ErbB4 deletion predisposes to development of metabolic syndrome in mice. American Journal of Physiology: Endocrinology and Metabolism 2018315 E583-E593. (https://doi.org/10.1152/ajpendo.00166.2018)

20 Xiong X, Wang X, Lu Y, Wang E, Zhang Z, Yang J, Zhang H \& Li X. Hepatic steatosis exacerbated by endoplasmic reticulum stressmediated downregulation of FXR in aging mice. Journal of Hepatology 201460 847-854. (https://doi.org/10.1016/j.jhep.2013.12.003)

21 Guo L, Zhang P, Chen Z, Xia H, Li S, Zhang Y, Kobberup S, Zou W $\&$ Lin JD. Hepatic neuregulin 4 signaling defines an endocrine checkpoint for steatosis-to-NASH progression. Journal of Clinical Investigation 2017127 4449-4461. (https://doi.org/10.1172/ JCI96324)

22 Chen LL, Peng MM, Zhang JY, Hu X, Min J, Huang QL \& Wan LM. Elevated circulating neuregulin4 level in patients with diabetes. Diabetes/Metabolism Research and Reviews 201733 e2870. (https://doi. org/10.1002/dmrr.2870)

23 Kang YE, Kim JM, Choung S, Joung KH, Lee JH, Kim HJ \& Ku BJ. Comparison of serum neuregulin 4 (Nrg4) levels in adults with newly diagnosed type 2 diabetes mellitus and controls without diabetes. Diabetes Research and Clinical Practice 2016117 1-3. (https://doi. org/10.1016/j.diabres.2016.04.007)

24 Kurek Eken M, Yayla Abide C, Sahin Ersoy G, Altun Ensari T, Pekin O \& Cevik O. Clinical significance of neuregulin 4 (NRG4) in gestational diabetes mellitus. Gynecological Endocrinology 201834 605-608. (https://doi.org/10.1080/09513590.2017.1420772)

25 Temur M, Calan M, Akşit M, Yılmaz Ö, Çift T, Akselim B, Dinçgez Çakmak B \& Üstünyurt E. Increased serum neuregulin 4 levels in women with polycystic ovary syndrome: a case-control study. Ginekologia Polska 201788 517-522. (https://doi.org/10.5603/ GP.a2017.0095)

26 Yan PJ, Xu Y, Wan Q, Feng J, Li H, Gao CL, Yang J, Zhong HH $\&$ Zhang ZH. Decreased plasma neuregulin 4 concentration is associated with increased high-sensitivity C-reactive protein in newly diagnosed type 2 diabetes mellitus patients: a cross-sectional study. Acta Diabetologica 201754 1091-1099. (https://doi.org/10.1007/ s00592-017-1044-4)

27 Cai C, Lin M, Xu Y, Li X, Yang S \& Zhang H. Association of circulating neuregulin 4 with metabolic syndrome in obese adults: a cross-sectional study. BMC Medicine 201614 165. (https://doi. org/10.1186/s12916-016-0703-6)

28 Jiang J, Lin M, Xu Y, Shao J, Li X, Zhang H \& Yang S. Circulating neuregulin 4 levels are inversely associated with subclinical cardiovascular disease in obese adults. Scientific Reports $2016 \mathbf{6} 36710$. (https://doi.org/10.1038/srep36710)

29 Liu SQ, Tefft BJ, Roberts DT, Zhang LQ, Ren Y, Li YC, Huang Y, Zhang D, Phillips HR \& Wu YH. Cardioprotective proteins upregulated in the liver in response to experimental myocardial ischemia. American Journal of Physiology: Heart and Circulatory https://ec.bioscientifica.com https://doi.org/10.1530/EC-19-0175 (c) 2019 The authors Published by Bioscientifica Ltd

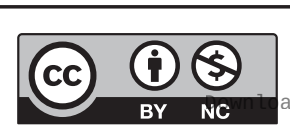

This work is licensed under a Creative Commons Attribution-NonCommercial 4.0 International License. ded from Bioscientifica.com at 04/26/2023 05:51:27AM 
Physiology 2012303 1446-1458. (https://doi.org/10.1152/ ajpheart.00362.2012)

30 Mullur R, Liu YY \& Brent GA. Thyroid hormone regulation of metabolism. Physiological Reviews 201494 355-382. (https://doi. org/10.1152/physrev.00030.2013)

31 Weiner J, Hankir M, Heiker JT, Fenske W \& Krause K. Thyroid hormones and browning of adipose tissue. Molecular and Cellular Endocrinology 2017458 156-159. (https://doi.org/10.1016/j. mce.2017.01.011)

32 Comte B, Vidal H, Laville M \& Riou JP. Influence of thyroid hormones on gluconeogenesis from glycerol in rat hepatocytes: a dose-response study. Metabolism: Clinical and Experimental 199039 259-263. (https://doi.org/10.1016/0026-0495(90)90044-D)

33 Park EA, Song S, Vinson C \& Roesler WJ. Role of CCAAT enhancerbinding protein beta in the thyroid hormone and cAMP induction of phosphoenolpyruvate carboxykinase gene transcription. Journal of Biological Chemistry 1999274 211-217. (https://doi.org/10.1074/ jbc.274.1.211)

34 Kowalik MA, Columbano A \& Perra A. Thyroid hormones, thyromimetics and their metabolites in the treatment of liver disease.
Frontiers in Endocrinology 20189 382. (https://doi.org/10.3389/ fendo.2018.00382)

35 Cable EE, Finn PD, Stebbins JW, Hou J, Ito BR, van Poelje PD, Linemeyer DL \& Erion MD. Reduction of hepatic steatosis in rats and mice after treatment with a liver-targeted thyroid hormone receptor agonist. Hepatology 200949 407-417. (https://doi.org/10.1002/ hep.22572)

36 Sinha RA, Singh BK \& Yen PM. Thyroid hormone regulation of hepatic lipid and carbohydrate metabolism. Trends in Endocrinology and Metabolism 201425 538-545. (https://doi.org/10.1016/j. tem.2014.07.001)

37 Comas F, Martínez C, Sabater M, Ortega F, Latorre J, Díaz-Sáez F, Aragonés J, Camps M, Gumà A, Ricart W, et al. Neuregulin 4 is a novel marker of beige adipocyte precursor cells in human adipose tissue. Frontiers in Physiology 2019 10 39. (https://doi.org/10.3389/ fphys.2019.00039)

38 Zhang L, Bai M, Tang H, Zhou F, Zhu Q, Wang S, Zhu K, Liu Q, Liu Y, Wang X, et al. Role of hepatic neuregulin 4 in the regulation of gluconeogenesis in mice. Life Sciences 2019217 185-192. (https:// doi.org/10.1016/j.lfs.2018.12.006)

Received in final form 22 April 2019

Accepted 7 May 2019

Accepted Preprint published online 7 May 2019 https://ec.bioscientifica.com

https://doi.org/10.1530/EC-19-0175
(C) 2019 The authors Published by Bioscientifica Ltd

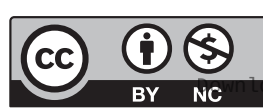

This work is licensed under a Creative Commons Attribution-NonCommercial 4.0 International License. ded from Bioscientifica.com at 04/26/2023 05:51:27AM via free access 